\title{
Identifying thresholds and ceilings in plant community recovery for optimal management of widespread weeds
}

\author{
F. Dane Panetta', Luke S. O’Loughlin ${ }^{2,3}$, Ben Gooden ${ }^{4,5}$ \\ I School of Agriculture and Food, The University of Melbourne, Parkville, VIC 3010, Australia 2 Fenner School \\ of Environment \& Society, The Australian National University, Canberra, ACT 0200, Australia 3 School of \\ Environmental Science, Charles Sturt University, Albury, NSW 2640, Australia 4 Health and Biosecurity, \\ Commonwealth Scientific and Industrial Research Organisation (CSIRO), GPO Box 1700, Canberra, ACT \\ 2601, Australia 5 Centre for Sustainable Ecosystem Solutions, Faculty of Science, Medicine and Health, \\ University of Wollongong, Wollongong, NSW 2522, Australia
}

Corresponding author: F. Dane Panetta (dane.panetta@gmail.com)

Academic editor: L. Foxcroft | Received 24 October 2018 | Accepted 21 January 2019 | Published 6 February 2019

Citation: Panetta FD, O'Loughlin LS, Gooden B (2019) Identifying thresholds and ceilings in plant community recovery for optimal management of widespread weeds. NeoBiota 42: 1-18. https://doi.org/10.3897/neobiota.42.30797

\begin{abstract}
A substantial body of work underlies the theory and practice of early intervention in the management of invasive alien plants, but less attention has been paid to the strategic management of widespread weeds, especially in the context of natural asset recovery. The assumption lingers amongst some researchers and land managers that removing weeds will automatically lead to positive biodiversity outcomes, with the more weed removed, the better the outcome. However, this is often not the case, particularly for long-established weed species whose dominance has created impoverished communities with little capacity for passive recovery. A common result may be wasted investment in weed control and, in the extreme, net negative impacts upon asset values. We present a conceptual model for the management of weed-impacted assets, plus guidance for its application, with a view to improving asset recovery practice. Weed removal should be calibrated by asset recovery, which may mean not seeking to completely remove a weed at a given spatial scale. Our model focusses on weed removal that is enough to initiate asset recovery, but not more than is necessary to promote maximum expression of asset resilience, particularly in the context of secondary invasions. Optimal management efficiency will involve a proportional allocation of resources to control, monitoring and revegetation activities that is appropriate to the stage of asset recovery, as well as a willingness to revise a management goal if the original one cannot be achieved within existing constraints on resources.
\end{abstract}

Copyright F. Dane Panetta et al. This is an open access article distributed under the terms of the Creative Commons Attribution License (CC BY 4.0), which permits unrestricted use, distribution, and reproduction in any medium, provided the original author and source are credited. 


\section{Keywords}

Biodiversity, natural asset recovery, resilience, resistance, secondary invasion, weed management

\section{Introduction}

Considerable attention has been paid to early intervention in the management of invasive alien plants, especially those whose potential impact upon the values of natural ecosystems is high (Panetta and Cacho 2014, Panetta 2015, Blood and James 2016, Wilson et al. 2017). Procedures for risk assessment and the planning, implementation and evaluation of incursion management strategies (e.g. eradication and containment) are well-established (Wilson et al. 2017). Conversely, after invasive plants become widely established, the focus of management necessarily switches to asset protection, with the aim of protecting the greatest ecological values of threatened communities (Downey et al. 2010, Shackelton et al. 2017). Where extirpation of an invader is not feasible, asset protection can be achieved proactively by maintaining its abundance below an impact threshold, defined as the abundance beyond which the asset in question (e.g. native plant community diversity) becomes increasingly degraded with further increases in invader abundance (Panetta and Gooden 2017). This approach relies upon the resistance (Nimmo et al. 2015) of natural ecosystems to invasion, i.e. their ability to maintain biodiversity in the presence of an invader at abundances below the impact threshold.

Elsewhere, a common goal of management is to improve biodiversity values of impacted communities that have become impoverished through the dominance of invasive plants over time (Reid et al. 2009, Kettenring and Adams 2011), although other management goals (such as restoration of native species cover or provision of ecosystem services) may be pursued, depending upon site history and landscape context (Gaertner et al. 2012). In such cases the approach to management is essentially reactive and highlights the importance of plant community resilience in restoration (i.e. the capacity for recovery once the invader has been removed). Two pervasive assumptions underpin weed management for the recovery of impacted biodiversity: (1) that the weed should be removed entirely from the focal area of interest (Reid et al. 2009); and (2) that the removal of the weed will enable recovery of the asset (e.g. Vosse et al. 2008). Some progress has been made regarding the second question, particularly in our understanding that weed removal technique may modulate asset recovery trajectories (Mason and French 2007, Flory and Clay 2009). However, the assumption persists that removing a weed entirely will yield the best outcome for biodiversity, and the retention of a weed at any level of abundance within the target control area over time is unacceptable.

In this paper, we show how a greater focus on the response of native biodiversity assets to control actions may improve management outcomes for long-established weed species. We develop a conceptual model that can be used to evaluate asset recovery in response to weed management where operational resources are scarce and the capacity for passive restoration is unknown. Our approach integrates three key sets of questions and considerations: 
1. What is the potential for passive recovery of a given asset, and how much weed removal is necessary to achieve this potential? Here, we consider impact thresholds of weed removal on the regenerating asset and identify ceilings to passive recovery, after which active regeneration will be required to improve asset condition. The role of community resilience to invasion in determining the relative importance of passive and active asset recovery is highlighted.

2. What is the likely impact of the establishment of other invaders facilitated by management ("secondary invasion"; Pearson et al. 2016a, O'Loughlin and Green 2017, Nsikani et al. 2018) upon asset recovery, and under what circumstances might secondary invasions force a reconsideration of management goals? Here, we highlight that secondary invasions are among the most common and pervasive outcomes of weed management and, as such, need to be accounted for in any model that considers asset response to primary weed removal.

3. How should management effort be allocated over time between the main activities (weed control, monitoring and revegetation) associated with asset recovery? Here, we define three stages of asset recovery that differ according to the optimal relative allocation to various activities.

Answers to these questions will assist land managers to determine the most costeffective means of achieving articulated management goals and provide a basis for goal modification if required. We focus on the case of a single invasive species but see no reason why our conclusions would differ qualitatively in the presence of multiple primary invaders. However, we acknowledge the current deficiency of empirical observations relevant to our model and thus offer it for the purposes of informing management practice and stimulating further research.

\section{Why weed removal actions should be guided by asset recovery}

A common theme in the control of invasive species is a failure by researchers and practitioners to take a whole-of-community approach to evaluating the efficacy of weed management in recovering target assets (Kopf et al. 2017). Managers frequently monitor target weed responses to management as a surrogate for native asset responses that remain unmeasured (Reid et al. 2009; Foster et al. 2019), and financial constraints often preclude monitoring beyond one or a few growing seasons (Kettenring and Adams 2011). Similarly, reviews and meta-analyses of invasive plant control research have found that while most studies measured the effect of management on the target invasive species, far fewer also assessed the response of native plant species (estimates range from 19\% to 30\%) (Reid et al. 2009, Kettenring and Adams 2011; for a recent example of native species response over the medium term see Ruwanza et al. 2018). Emphasis on the response of the target invasive species commonly finds expression in project operational milestones, for example area of weed infestation cleared, with an assumption that weed removal benefits resident biodiversity. Subsequently, there is very 
limited understanding of the spatial or temporal scales over which native communities recover post invasion, whether recovery progresses along a trajectory towards a desired native condition, or if the method optimal for weed removal is also optimal for asset recovery. Moreover, impacted communities are often fundamentally altered to the extent that the pre-invasion condition (as observed in non-invaded reference sites; Hudson et al. 2014, McDonald et al. 2016) may not be readily, or ever, restored.

It is surprising that the idea of a strong link between weed removal and asset recovery persists, given that examples of successful passive restoration of invaded communities are extremely rare (Pearson et al. 2016a, Prior et al. 2018). Passive restoration usually succeeds only when the native plant community has a high degree of natural resilience to invasion, the surrounding landscape provides high native propagule pressure, and disturbance is not severe (Holl and Aide 2011). Natural resilience is likely a function of the period over which a community has been invaded, in situ persistence of native species in the form of underground vegetative propagules or seed banks, and the potential for native species immigration post invasion. Optimising weed management for the restoration of invaded communities therefore hinges upon knowledge of recovery trajectories, responses to weed management extent and method, and identifying limitations to passive regeneration beyond which active revegetation will be required.

Numerous factors contribute to the difficulty of effective passive restoration. These include legacy effects of invasion (Yelenik et al. 2004, Corbin and D'Antonio 2012, Gioria and Pyšek 2016), secondary invasions (Kettenring and Adams 2011, Pearson et al. 2016a, González et al. 2017a), non-target effects of invader control (Mason and French 2007, Rinella et al. 2009, Skurski et al. 2013), and variation in the resilience of the community (Prior et al. 2018). Also to be considered are the positive effects that some invaders have, such as the nesting sites and protection afforded by invasive shrub species to birds, reptiles and small mammals in disturbed landscapes (D'Antonio and Meyerson 2002). Management of long-established invaders requires an ecosystems outcome approach that takes all of these factors into consideration (D'Antonio and Meyerson 2002; Kopf et al. 2017). Setting realistic and achievable management goals for restoration is essential (Hobbs 2007) and goals need to be considered in the dual context of asset condition and available resources. Proper monitoring of the asset recovery response to management actions should help managers to invest limited resources most efficiently and cost-effectively.

\section{Important thresholds and ceilings in restoration responses to weed management}

Currently, guidelines have been formulated for impact and action thresholds where plant invaders are managed proactively; i.e. before they have reached enough abundance to impact the target natural asset (Panetta and Gooden 2017). However, there appears to have been no consideration of thresholds where the reactive management goal is to improve the biodiversity status of communities that are already impacted by 
a widespread invader. Our model comprises three main points, which taken together comprise asset responses to weed removal (see details in Box 1 for detailed explanation of the model, and a glossary of key terms in Box 2):

\section{Asset recovery threshold}

The first is an asset recovery threshold, which denotes the minimum amount of a weed that must be removed to initiate passive asset recovery (e.g. near point $\mathbf{1}$ on curves $\mathbf{A}, \mathbf{B}$ and $\mathbf{D}$, and point $\mathbf{3}$ on curve $\mathbf{C}$; Box 1). The position of this threshold (corresponding to the area of weed removed) will depend upon the spatial pattern of propagules of native species, occurring in situ or arriving via immigration post weed removal. High resilience may be conferred by a dense, species rich native seed bank, with seedling recruitment into the standing vegetation commencing after the target weed is removed.

\section{Asset recovery ceiling / weed removal ceiling}

The second is an asset recovery ceiling or weed removal ceiling, beyond which asset condition will not passively improve with further investment in weed removal (point $\mathbf{2}$ on curve A, plus analogous inflection points on the other curves; Box 1). In the most favourable case, i.e. where community resilience is very high, the asset recovery ceiling will coincide with the most desirable uninvaded native state (point $\mathbf{2}$ on curve $\mathbf{A}$; Box 1). Otherwise, a recovery deficit (interval $\mathbf{i}$; Box 1 ) will occur, after which active intervention, such as planting seeds or nursery-grown seedlings of some native species, will be required to facilitate recovery to the desired native reference state. An asset recovery ceiling may be reached if certain plant species with short-lived seeds or short-distance dispersal mechanisms are eliminated by the invader and subsequently are unable to recolonise the site.

\section{Management impact threshold}

The third is a management impact threshold (point $\mathbf{4}$ on curve $\mathbf{D}$; Box 1), which occurs when further weed removal, substantially beyond the asset recovery ceiling, would cause the asset to deteriorate, owing to unintended negative effects of control actions. Such effects may be direct, such as damage to native plant species due to herbicide drift, plus soil compaction, erosion and nutrient loss. They may also be indirect, for example by promoting secondary invaders that suppress native regeneration and may be more difficult to manage than the target weed species (Cox and Allen 2008, Ortega and Pearson 2010). Indirect negative impacts may arise as well through a loss of unforeseen beneficial effects of the targeted weed (e.g. the nesting sites and protection afforded by invasive shrub species to birds, reptiles and small mammals; D'Antonio 
Box I. Conceptual diagram of the model for the recovery of weed-impacted natural assets.

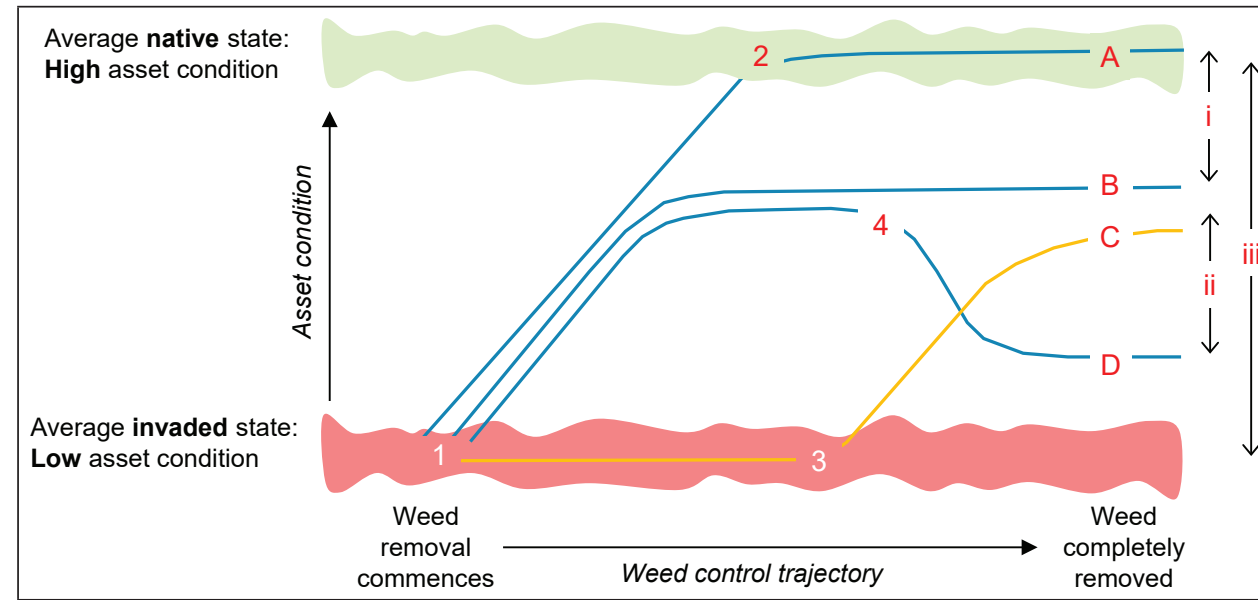

Axes

The $y$-axis represents a sliding scale of vegetation community condition between an average invaded state (red zone) and an average non-invaded, native reference state (green zone). The origin at point $\mathbf{1}$ represents a state $100 \%$ dissimilar to the non-invaded, native condition (e.g. a weed-dominated area that contains none or a different suite of native species to those found in non-invaded reference areas). It is assumed that a non-invaded, native state comprises higher asset condition than weed-dominated areas. Impact of invasion is measured as the magnitude of difference between the average non-invaded state (green zone) and the average invaded state (red zone), represented by interval iii.

The $x$-axis represents a sliding scale of weed removal. The curves $\mathbf{A}, \mathbf{B}, \mathbf{C}$ and $\mathbf{D}$ represent different patterns of vegetation community response to weed removal (i.e. regeneration trajectories). Vegetation community regeneration in response to weed removal will vary as a function of resilience to invasion, which is defined as the extent of recovery of the asset post invasion (Nimmo et al. 2015). Blue curves (A, B and D) represent communities with relatively high resilience to invasion, while the orange curve $\mathbf{C}$ represents a community with relatively low resilience (see description below). For simplicity, we have presented resistance to invasion (i.e. degree of community change in response to invasion, interval iii; Nimmo et al. 2015) as equal for all curves, hence why the level of impact is equivalent at point $\mathbf{1}$ for all curves at the maximum level of weed abundance before removal of the weed commences.

\section{Regeneration trajectories}

Curve A represents the most resilient community (the best-case scenario for managers), because the native vegetation begins to recover very soon after weed removal commences (i.e. the asset recovery threshold occurs close to point $\mathbf{1}$ ), any amount of weed removal facilitates native vegetation recovery, and full recovery to the reference native state is achieved. An asset recovery ceiling occurs at point $\mathbf{2}$, beyond which asset condition will not improve with any further investment in weed removal. This point can also be considered as a weed removal ceiling, the latter being causal and asset recovery its effect.

Curve $\mathbf{B}$ is similar initially to curve $\mathbf{A}$ in that removal of the weed initiates rapid, linear asset recovery near point 1. However, for curve $\mathbf{B}$, the community is relatively less resilient to invasion because the response trajectory does not reach the maximum level of the desired native reference state by the time the asset recovery ceiling is reached. This results in a recovery deficit (interval i) and represents the model space in which active intervention would be required to facilitate full community recovery (e.g. planting nursery-grown seedlings or seed addition).

Curve $\mathbf{C}$ represents a community with a much-reduced level of resilience, since regeneration of the asset only commences after a much greater proportion of the weed is removed from the invaded site (i.e. asset recovery threshold at point 3).

Curve $\mathbf{D}$ represents a scenario where weed removal promotes asset recovery until a weed removal ceiling is reached, but thereafter inhibits asset recovery due to disturbance effects of the control technique being used to remove the weed. In this case point $\mathbf{4}$ represents a management impact threshold and interval ii represents the net effects of management that balances benefits of weed removal (maximum at point 4) with negative effects of control action used to remove the weed. 
Box 2. Glossary of key terminology.



and Meyerson 2002). In extreme cases, extending weed removal beyond the asset recovery ceiling could result in the condition of the native asset regressing to a state that is more degraded than its initial condition. In more moderate cases, reducing weed cover beyond the management impact threshold would not only reverse gains made to asset condition (note the decline in asset condition beyond point $\mathbf{4}$ on curve $\mathbf{D}$ ), but also waste money, time and resources that could otherwise be allocated to restoration and maintenance at the site in the future, or weed control elsewhere. It follows that this threshold is one that practitioners should take precautions not to breach.

\section{Secondary invasion: a fundamental impediment to asset recovery}

As was foreshadowed in the Introduction, the responses of other invaders to primary weed removal will often play a critical role in determining the outcome of an asset recovery effort. In long-invaded sites, the seed bank is often dominated by non-native species (O'Loughlin et al. 2014; Gioria and Pyšek 2016) and removal of the targeted weed will likely give rise to secondary invasions by one or more species. This is a prime reason why restoration efforts fail: in a meta-analysis of 60 cases from 38 studies Pearson et al. (2016a) found that control efforts markedly reduced primary invader abundance, but the consequence of primary invader control was usually secondary invasion, not the recovery of native species. The increase in secondary invaders was associated with a mean effect size twice that for native plants, which increased only weakly. Pearson et al. (2016a) concluded that primary invader suppression was the key factor in the release of secondary invaders and argued that management strategies are required that anticipate and suppress secondary invaders as part of site restoration. 
Sometimes the abundance of secondary invaders will decrease over time post control, even in the absence of further management intervention. In some mesic environments, for example, secondary invasion comprises shade intolerant, short-lived ephemerals that are displaced as native vegetation develops. Gooden et al. (2009) found that after the removal of the non-native shrub Lantana camara in wet sclerophyll forest on the southeast coast of Australia, secondary invaders comprised transient annual and biennial herbs that were unlikely to impact on regenerating native species. Similarly, there was only a temporary spike in exotic species richness in a New Zealand wetland following the aerial application of glyphosate to a Salix cinerea infestation (Burge et al. 2017). In other situations, however, the potential impact of secondary invaders may be greater than that of the targeted weed (Dickens et al. 2016, Pearson et al. 2016b), or their management more difficult. The second possibility would appear to be more important in the context of plant community recovery. Cox and Allen (2008) found that when non-native annual grasses were controlled by a grass-selective herbicide in southern California coastal sage scrub, non-native forbs, especially species of Erodium, increased in cover. The effects of Erodium on the emergence and establishment of native species are variable (see references in Cox and Allen (2008)) but the further option of selective removal of these non-native forbs with herbicides is clearly not available. In bunchgrass communities of western Montana, Ortega and Pearson (2010) found that control of the invasive forb Centaurea stoebe with picloram was effective on the targeted species, but afterwards dominance shifted to the non-native grass Bromus tectorum, at the expense of native grasses. Thus, application of grass-selective and broadleaf-selective herbicides in these two cases led to difficult-to-manage secondary invasions by the complementary life form.

\section{Using this model in practice: monitoring, secondary invasions and re- covery deficits}

Where monitoring and evaluation of weed control programs is undertaken, this commonly occurs at the completion of the program (FD Panetta, personal observations). However, monitoring and evaluation during programs is far more important, potentially providing evidence of significant off-target effects on the asset, or other reasons to modify management actions to achieve stated goals (Hulme 2006, Field et al. 2007). Timely delivery of information of this sort can also help land managers to decide whether management goals as originally articulated are achievable. In the present case, only through appropriate monitoring can weed control actions be informed by asset recovery trajectories.

\section{Determining the asset recovery threshold}

Although multiple thresholds and ceilings are identified in the model, its practical implications are relatively straightforward. If the weed-impacted asset has any degree 
of natural resilience to invasion, its recovery threshold (i.e. the minimum level of weed removal necessary to initiate asset recovery) should be exceeded at some point early on during the weed removal process, so identification of this threshold will usually not be critical. However, practitioners need to have the capacity for substantial weed removal in the event that the recovery threshold is not reached until a large proportion of the weed population has been removed.

What is critically important is the weed removal ceiling that is associated with the asset recovery ceiling. If weed removal ceilings are properly identified during asset recovery operations, there will be less chance of: (a) wasting management effort through superfluous weed control, or (b) exceeding the management impact threshold, at which point the net effects of weed control would become negative (see point $\mathbf{4}$ on curve D; Box 1). Furthermore, management effectiveness will be improved when managers can redirect resources from unnecessary weed removal to active restoration efforts to bridge the recovery deficit. Several steps need to be taken prior to attempting asset recovery. Based upon an assessment of the asset's degraded condition prior to weed removal, the management goal must be clearly defined, i.e. what is the desired degree of asset improvement? Next, a monitoring schedule needs to be established, taking into consideration the variables that will be measured as a surrogate for asset recovery in response to weed removal, plus when monitoring will be undertaken (see below).

\section{Identifying the weed removal ceiling}

A logical approach for identifying the weed removal ceiling would be to remove the targeted weed incrementally, as illustrated in Figure 1. Incremental removal would contribute to suppression of the target weed and provide a means of assessing asset resilience (i.e. the size of the recovery deficit; see interval $\mathbf{i}$ in Box 1), as well as the potential for secondary invasion. The initial area subjected to weed removal, and the pattern of weed removal within the area, should be determined with a view of gaining an estimate of passive recovery potential. Contrary to the conventional practice of some contractors who expend a major proportion of the planned control effort to a single weed removal operation, a more suitable approach would involve weed removal operations that are staggered through time and space. Such a staged approach is usually undertaken by volunteer restoration practitioners, yet their valuable on-ground experiences are rarely integrated into broad weed management strategies at higher governance levels (O’Meara and Darcovich 2015, Peters et al. 2015, Pagès et al. 2019). Enough time should be allowed for the recruitment of native species after each operation. The time required for a proper assessment of the passive recovery response will vary according to environmental factors, especially rainfall incidence (Ogden and Rejmánek 2005, Cox and Allen 2008, González et al. 2017b) and the occurrence of critical germination cues, such as fire (Lindenmayer et al. 2015).

Evidence of asset resilience should be interpreted in the context of observations on the presence and nature of secondary invasions, especially the ease with which such 


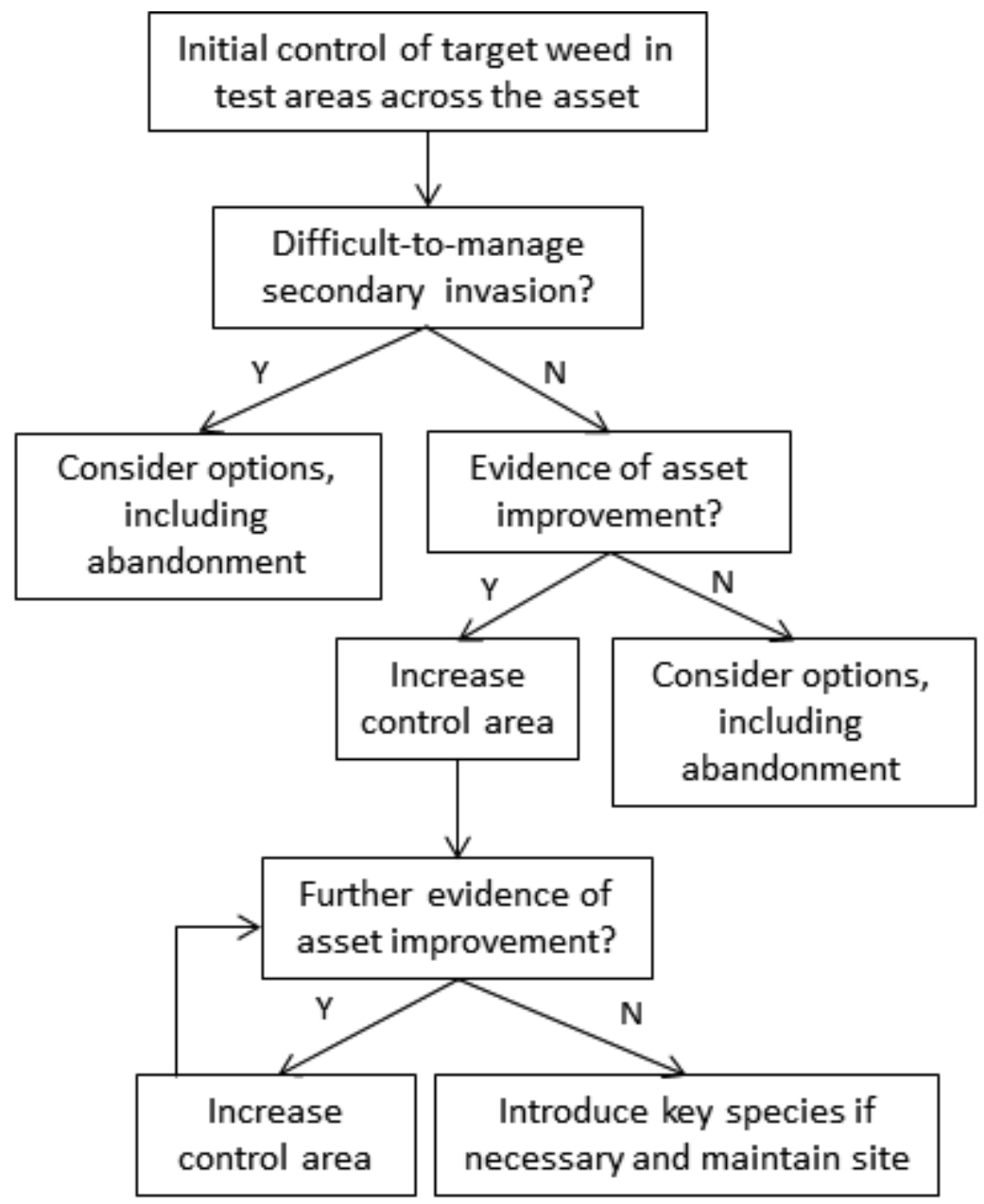

Figure I. Decision tree for determining primary weed removal ceilings. Evidence of asset improvement includes increases in native species richness and evenness, and increased similarity of community structure to that found in reference sites. If the asset response following initial weed removal includes problematic secondary invasions, reconsideration of the initial management goal may be appropriate.

invaders could be managed while maintaining the restoration objectives for the asset (Figure 1). As Pearson et al. (2016b, p. 16) state, "In situations when the likelihood of promoting problematic secondary invaders is high and mitigation strategies for such invaders are lacking, the no action management alternative may be advisable." Implementation of highly targeted control (e.g. treating individual plants) will reduce the size of management-induced disturbance, hence reducing the opportunity for secondary invasion (Pearson et al. 2016a).

The extent of active revegetation required will depend upon the level of community resilience to invasion. With high resilience, perhaps only a few key species (with emphasis on missing or poorly represented functional groups) will need to be introduced, 
either as seed or vegetative stock, for the asset to gain an acceptable level of similarity to non-invaded reference sites. Where low resilience is evident, the amount of active revegetation that occurs will depend upon the resources available for management. The potential for increasing biotic resistance to secondary invasion should also be considered when selecting species for reintroduction (Schuster et al. 2018). In many cases the availability of volunteer participation over long periods will be crucial to asset recovery (O’Meara and Darcovich 2015, Peters et al. 2015, McDonald et al. 2016, Pagès et al. 2019). Here, the costs of materials (e.g. native species seed and tube stock) will generally be small relative to the value of the voluntary labour component. In terms of total effort and investment, management options thus range from abandonment of asset recovery altogether to reintroduction of a number of native plant species (Figure 2).

\section{Dealing with asset recovery deficits}

Asset recovery activities can be partitioned between invader control, active revegetation and monitoring. In a successful restoration program, the relative allocation of total effort to these activities can be expected to change over time (Figure 2). While more than one activity will always be required in any one stage, the predominant activity will be weed control, revegetation and monitoring in Stages 1, 2 and 3 respectively. Irrespective of the management goal, Stages 1 and 3 in this scheme are potentially the least variable, with the predominant activities in Stages 1 and 3 being weed removal and monitoring, respectively. The nature of Stage 2, however, may vary significantly between assets, depending upon the size of the recovery deficit (see interval $\mathbf{i}$ in Box 1), which will determine the required allocation to revegetation (Figure 2). Land managers may decide that the recovery deficit is too large to address (but see O'Meara and Darcovich 2015, Peters et al. 2015, and Pagès et al. 2019 for cases of monitoring and asset recovery via the contributions made by volunteers over long periods), or the existence of legacy invader effects may render restoration to reference native conditions unfeasible-at least until such effects have been ameliorated. Where the recovery deficit is high and secondary invasion is a significant issue, asset recovery can effectively stall in Stage 1 (Figure 2), requiring a reconsideration of management goals.

Where the asset's recovery deficit is moderate, secondary invasion is minimal or easily managed and there are enough resources for revegetation, the duration of Stage 2 will depend upon the rates of establishment, survival and growth of the native species utilised in revegetation. In the case of a low recovery deficit (see curve $\mathbf{A}$ in Box 1 and Figure 2), however, Stage 2 may be brief or even absent.

Unless the goal of improving the biodiversity of assets is abandoned, an indefinite control effort will be required to prevent resurgence of the primary invader or emergence of a new one (Stage 3). In addition to factors such as the level of participation by local volunteers, the frequency of monitoring during Stage 3 will depend upon invader population dynamics, especially the time to reproduction (see Panetta 2015), the rate of biomass accumulation and levels of immigration from the surrounding landscape. 


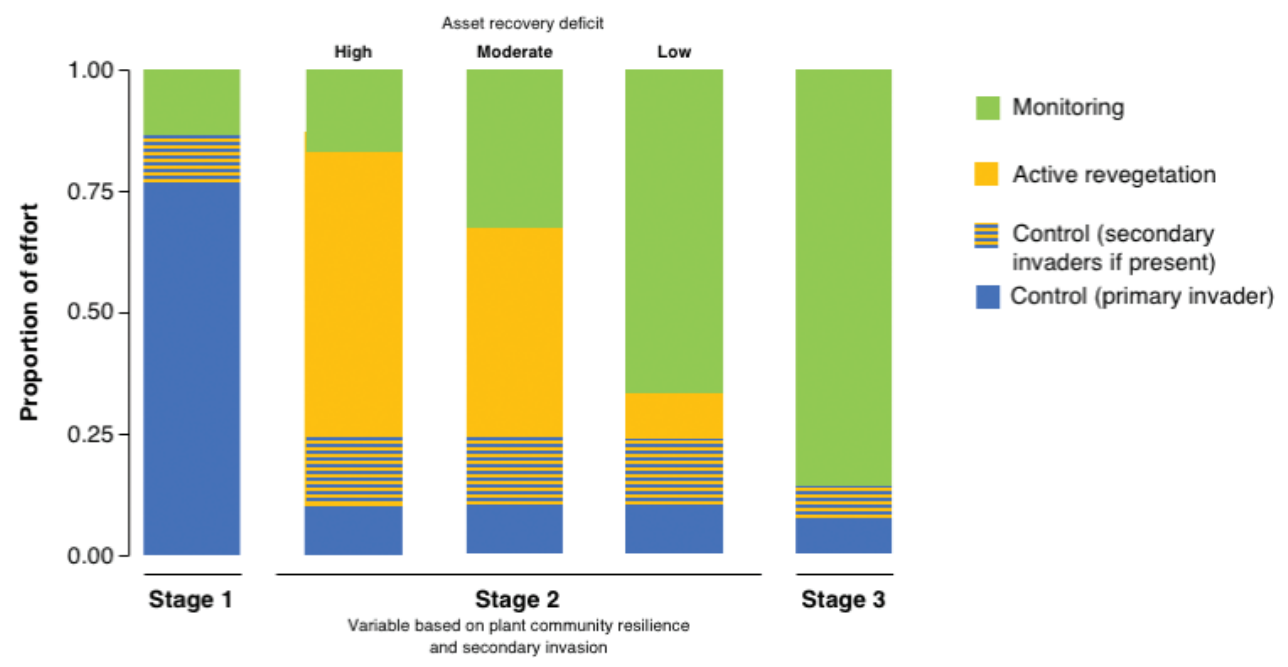

Figure 2. The proportional allocation of effort to various activities will change through time during asset recovery programs. The proportions of effort allocated to activities in Stage 2 with be dependent on identifying the asset recovery threshold and asset recovery ceiling specific to each program (see Box 1). A protracted requirement for the control of primary or secondary invasions indicates a stalled program that is unlikely to transition to Stage 2, demonstrating a need to reconsider the initial management goal. Note that values portrayed are for illustrative purposes only.

\section{Balancing the costs and benefits of asset recovery activities}

Incomplete evaluation of costs and benefits associated with invasive species management actions poses a key barrier to successful invasive species control (Kettenring and Adams 2011). Costs and benefits are most frequently considered in terms of methodology (i.e. the relative efficacy of control action in killing or preventing the reproduction or spread of invasive species) and the strategic allocation of resources (i.e. when, where and how much control should be applied to manage invasions) (Epanchin-Niell and Hastings 2010). Since repeated control methods are often required to manage invasive species effectively, the costs and benefits of specific control methods must be considered when implementing control programs (Meloche and Murphy 2006). Generally more emphasis has been placed on the costs of invasive species control than on the resultant benefits (e.g. increased native species richness and improved vegetation structure), as evidenced by the plethora of weed control studies or operations where evaluation has concerned target effects to the exclusion of asset recovery response (Reid et al. 2009, Kettenring and Adams 2011).

Only when the benefits resulting from targeted control activities are quantified will it be possible to make proper decisions regarding the management of weed-impacted assets. If there is no evidence of positive asset response after weed removal operations (see Figure 1), the costs of the operations will unquestionably outweigh the benefits. Costs will also exceed benefits should the total amount of weed removal breach the 
management impact threshold (see point $\mathbf{4}$ on curve $\mathbf{D}$ in Box 1 ), but if weed removal is incremental and monitoring is undertaken this outcome can be avoided. Positive impacts of the targeted invader (Kumschick et al. 2012, Blackburn et al. 2014) also need to be included in the calculus. With longstanding weed invasions, the primary task of the land manager is to ensure that the costs of weed control are equal to or less that the derived biodiversity benefits; timely assessment of asset recovery status is therefore an essential part of this.

It would be pointless to invest in $100 \%$ weed removal if this provides no additional benefit to biodiversity when compared to removal to a lower level (e.g. 50\% of initial abundance) and maintaining this level over time, especially when negative impacts of weed removal on the target asset are evident. However, there may be circumstances where total weed removal is appropriate. Here, subsequent asset recovery may be highly dependent on the quality and sensitivity of the weed-removal technique employed, which either promote or hinder seed bank initiation of community regeneration (Vosse et al. 2008). For example, the regeneration of fynbos vegetation in the Western Cape Province of South Africa was poorest when the woody invaders Pinus radiata and Hakea sericea were felled and then burned, owing to the excessive heat generated by large amounts of dead fuel (Holmes et al. 2000). In Colorado, mechanical clearing of Tamarix species using a Hydro-Ax (a piece of heavy equipment designed for mowing woody vegetation, leaving all debris on-site), did not cause a resurgence of Bromus tectorum and other invasive species, most likely due to the mulching effect (Sher et al. 2008). These two examples demonstrate that methods of broadscale weed removal may have consequences for both native species recruitment and the level of secondary invasion. Accumulated costs that greatly exceed apparent benefits signal a need for a change in the management goal; the options under consideration must include disinvestment.

\section{Concluding remarks}

The prevailing perspective on the management of invasive plants in natural assets is one in which the explicit focus is on implementation of invader control to obtain biodiversity benefits via an implicit focus on asset recovery. It is understandable, therefore, that the assumption took hold that invader removal would automatically lead to ecological improvement. With our model and its application we are proposing a subtle, but important, change in perspective, whereby the explicit focus is on recovery of the asset, based on direct monitoring of its response to invader control.

Prevalent funding models pose a major hindrance to the efficacy and cost efficiency of attempts to effect plant community recovery. Funding for invasive species control is often allocated in parcels that are unlinked to restoration or conservation funding (Prior et al. 2018). This helps to explain why population-level management, with the assumption that weed removal will automatically lead to biodiversity gains, has been a common approach to managing invaded natural ecosystems (Prior et al. 2018). Our proposed staged approach to asset recovery, one that combines assessments of both 
recovery deficit and the intrinsic limitations to recovery, runs counter to contractual arrangements that require relatively rapid expenditure of funds on primary weed control, presenting a potentially serious impediment to its implementation. This underlines the need for managers to work closely with volunteer restoration practitioners in designing and implementing weed removal programs. Moreover, the availability of accurate measures of the benefits of alien clearing may be key to identifying and accessing additional avenues for funding.

Realistic asset recovery goals can be formulated only by taking multiple factors into account, including legacy effects, asset recovery deficits, manageability of secondary invasions and, perhaps most critically, resource availability. The primary operational objectives should be to quantify the recovery deficit and the potential limits to recovery posed by secondary invasion. Land managers must always be prepared to revise management goals if timely monitoring and evaluation point towards a lower degree of asset recovery than was originally envisaged. Biodiversity benefits may still be obtained via a lesser asset recovery, but failing this, managers must be prepared to disinvest altogether.

\section{Acknowledgements}

We thank Guillaume Fried, Mirijam Gaertner, Mark Gardener and Nicola van Wilgen for their helpful suggestions on different drafts.

\section{References}

Blackburn TM, Essl F, Evans, T, Hulme PE, Jeschke JM, Kühn I, Kumschick S, Marková Z, Mrugała A, Nentwig W, Pergl J, Pyšek P, Rabitsch W, Ricciardi A, Richardson DM, Sendek A, Vilà M, Wilson JRU, Winter M, Genovesi P, Bacher S (2014) A unified classification of alien species based on the magnitude of their environmental impacts. PLoS Biology 12, e1001850, https://doi.org/10.1371/journal.pbio. 1001850

Blood K, James B (2016) Weeds at the early stage of invasion (WESI) project: Managing invasive plants at the early stage of invasion on public land in Victoria. Plant Protection Quarterly 31:6.

Burge OR, Bodmin KA, Clarkson BR, Bartlam S, Watts CH, Tanner CH (2017) Glyphosate redirects wetland vegetation trajectory following willow invasion. Applied Vegetation Science 20: 620-630. https://doi.org/10.1111/avsc. 12320

D'Antonio C, Meyerson LA (2002) Exotic plant species as problems and solutions in ecological restoration: A synthesis. Restoration Ecology 10: 703-713. https://doi.org/10.1046/ j.1526-100X.2002.01051.x

Dickens SM, Mangla S, Preston KL, Suding KN (2016) Embracing variability: Environmental dependence and plant community context in ecological restoration. Restoration Ecology 24: 119-127. https://doi.org/10.1111/rec.12288 
Downey PO, Williams MC, Whiffen LK, Auld BA, Hamilton MA, Burley AL, Turner PJ (2010) Managing alien plants for biodiversity outcomes - the need for triage. Invasive Plant Science and Management 3: 1-11. https://doi.org/10.1614/IPSM-09-042.1

Corbin JD, D'Antonio CM (2012) Gone but not forgotten? Invasive plants' legacies on community and ecosystem properties. Invasive Plant Science and Management 2012: 117-124. https://doi.org/10.1614/IPSM-D-11-00005.1

Cox RD, Allen EB (2008) Stability of exotic annual grasses following restoration efforts in southern California coastal sage scrub. Journal of Applied Ecology 45: 495-504. https:// doi.org/10.1111/j.1365-2664.2007.01437.x

Epanchin-Niell RS, Hastings A (2010) Controlling established invaders: integrating economics and spread dynamics to determine optimal management. Ecology Letters 13: 528-541. https://doi.org/10.1111/j.1461-0248.2010.01440.x

Field SA, O’Connor PJ, Tyre AJ, Possingham HP (2007) Making monitoring meaningful. Austral Ecology 32: 485-491. https://doi.org/10.1111/j.1442-9993.2007.01715.x

Flory SL, Clay K (2009) Invasive plant removal method determines native plant community responses. Journal of Applied Ecology 46: 434-442. https://doi.org/10.1111/j.13652664.2009.01610.x

Foster CN, O’Loughlin LS, Sato CF, Westgate MJ, Barton PS, Pierson JC, Balmer JM, Catt G, Chapman J, Detto T, Hawcroft A, Jones G, Kavanagh RP, McKay M, Marshall D, Moseby KE, Perry M, Robinson D, Seddon JA, Tuft K, Lindenmayer DB (2019) How practitioners integrate decision triggers with existing metrics in conservation monitoring. Journal of Environmental Management 230: 94-101. https://doi.org/10.1016/j.jenvman.2018.09.067

Gaertner M, Holmes PM, Richardson DM (2012) Biological invasions, resilience and restoration. In: van Andel J, Aronson J (Eds) Restoration Ecology: The New Frontier. John Wiley \& Sons, Ltd., Chichester, 265-280. https://doi.org/10.1002/9781118223130.ch20

Gioria M, Pyšek P (2016) The legacy of plant invasions: changes in the soil seed bank of invaded plant communities. BioScience 66: 40-53. https://doi.org/10.1093/biosci/biv165

González E, Sher AA, Anderson RM, Bay RF, Bean DW, Bissonnete GJ, Cooper DJ, Dohrenwend K, Eichhorst KD, El Waer H, Kennard DK (2017a) Secondary invasions of noxious weeds associated with control of invasive Tamarix are frequent, idiosyncratic and persistent. Biological Conservation 213: 106-114. https://doi.org/10.1016/j.biocon.2017.06.043

González E, Sher AA, Anderson RM, Bay RF, Bean DW, Bissonnete GJ, Bourgeois B, Cooper DJ, Dohrenwend K, Eichhorst KD, El Waer, H, Kennard DK, Harms-Weissinger R, Henry AL, Makarick LJ, Ostoja SM, Reynolds LV, Robinson WW, Shafroth PB (2017b) Vegetation response to invasive Tamarix control in southwestern US rivers: a collaborative study including 416 sites. Ecological Applications 27: 1789-1804. https:// doi.org/10.1002/eap.1566

Gooden B, French K, Turner PJ (2009) Invasion and management of a woody plant, Lantana camara L., alters vegetation diversity within wet sclerophyll forest in southeastern Australia. Forest Ecology and Management 257: 960-967. https://doi.org/10.1016/j. foreco.2008.10.040

Hobbs RJ (2007) Setting effective and realistic restoration goals: key directions for research. Restoration Ecology 15: 354-357. https://doi.org/10.1111/j.1526-100X.2007.00225.x 
Holl KD, Aide TM (2011) When and where to actively restore ecosystems? Forest Ecology and Management 261(10): 1558-1563. https://doi.org/10.1016/j.foreco.2010.07.004

Holmes PM, Richardson DM, Van Wilgen BW, Gelderblom C (2000) Recovery of South African fynbos vegetation following alien woody plant clearing and fire: implications for restoration. Austral Ecology 25: 631-639. https://doi.org/10.1111/j.1442-9993.2000. tb00069.x

Hudson JR, Hanula JL, Horn S (2014) Impacts of removing Chinese privet from riparian forests on plant communities and tree growth five years later. Forest Ecology and Management 324: 101-108. https://doi.org/10.1016/j.foreco.2014.04.013

Hulme PE (2006) Beyond control: wider implications for the management of biological invasions. Journal of Applied Ecology 43: 835-847. https://doi.org/10.1111/j.13652664.2006.01227.x

Kettenring KM, Adams CR (2011) Lessons learned from invasive plant control experiments: a systematic review and meta-analysis. Journal of Applied Ecology 48: 970-979. https://doi. org/10.1111/j.1365-2664.2011.01979.x

Kopf RK, Nimmo DG, Humphries P, Baumgartner LJ, Bode M, Bond NR, Byrom AE, Cucherousset J, Keller RP, King AJ, McGinness HM, Moyle PB, Olden JD (2017) Confronting the risks of large-scale invasive species control. Nature Ecology \& Evolution 1: 0172. https://doi.org/10.1038/s41559-017-0172

Kumschick S, Bacher S, Dawson W, Heikkilä J, Sendek A, Pluess T, Robinson TB, Kühn I (2012) A conceptual framework for prioritization of invasive alien species for management according to their impact. Neobiota 15: 69-100. http://dx.doi.org/10.3897/ neobiota. 15.3323

Lindenmayer, DB, Wood J, MacGregor C, Buckley YM, Dexter N, Fortescue M, Hobbs RJ, Catford JA (2015) A long-term experimental case study of the ecological effectiveness and cost effectiveness of invasive plant management in achieving conservation goals: Bitou bush control in Booderee National Park in eastern Australia. PLoS One 10(6): e0128482.

McDonald T, Jonson J, Dixon KW (2016) National standards for the practice of ecological restoration in Australia. Restoration Ecology 24: S4-S32. https://doi.org/10.1111/ emr. 12202

Mason TJ, French K (2007) Management regimes for a plant invader differentially impact resident communities. Biological Conservation 136: 246-259. https://doi.org/10.1016/j. biocon.2006.11.023

Meloche C, Murphy SD (2006) Managing tree-of-heaven (Ailanthus altissima) in parks and protected areas: a case study of Rondeau Provincial Park (Ontario, Canada). Environmental Management 37: 764-772. https://doi.org/10.1007/s00267-003-0151-x

Nimmo DG, Mac Nally R, Cunningham SC, Haslem A, Bennett AF (2015) Vive la résistance: reviving resistance for $21^{\text {st }}$ century conservation (2015) Trends in Ecology \& Evolution 30: 516-523. https://doi.org/10.1016/j.tree.2015.07.008

Nsikani MM, van Wilgen BW, Gaertner M (2018) Barriers to ecosystem restoration presented by soil legacy effects of invasive alien $\mathrm{N}_{2}$-fixing woody species: implications for ecological restoration. Restoration Ecology 26: 235-244. https://doi.org/10.1111/rec.12669 
Ogden JE, Rejmánek M (2005) Recovery of native plant communities after the control of a dominant invasive plant species, Foeniculum vulgare: implications for management. Biological Conservation 125: 427-439. https://doi.org/10.1016/j.biocon.2005.03.025

O'Loughlin LS, Green PT (2017) Secondary invasion: When invasion success is contingent on other invaders altering the properties of recipient ecosystems. Ecology and Evolution 7: 7628-7637. https://doi.org/10.1002/ece3.3315

O'Loughlin LS, Green PT, Morgan JW (2014) What potential is there for regeneration of native species from the soil seed bank in Coast Tea Tree-dominated scrub? Ecological Management and Restoration 15: 80-83. https://doi.org/10.1111/emr.12077

O’Meara J, Darcovich K (2015) Twelve years on: ecological restoration and rehabilitation at Sydney Olympic Park. Ecological Management \& Restoration 16: 14-28. https://doi. org/10.1111/emr.12150

Ortega YK, Pearson DE (2010) Effects of picloram application on community dominants vary with initial levels of spotted knapweed (Centaurea stoebe) invasion. Invasive Plant Science and Management 3: 70-80. https://doi.org/10.1614/IPSM-09-015.1

Pagès M, Fischer A, van der Wal R, Lambin X (2019) Empowered communities or "cheap labour"? Engaging volunteers in the rationalised management of invasive alien species in Great Britain. Journal of Environmental Management 229: 102-111. https:/doi. org/10.1016/j.jenvman.2018.06.053

Panetta FD (2015) Weed eradication feasibility: lessons of the $21^{\text {st }}$ century. Weed Research 55: 226-238. https://doi.org/10.1111/wre.12136

Panetta FD, Cacho OJ (2014) Designing weed containment strategies: An approach based on feasibilities of eradication and containment. Diversity and Distributions 20: 555-566. https://doi.org/10.1111/ddi.12170

Panetta FD, Gooden B (2017) Managing for biodiversity: impact and action thresholds for invasive plants in natural ecosystems. NeoBiota 34: 53-66. https://doi.org/10.3897/neobiota.34.11821

Pearson DE, Ortega YK, Runyon JB, Butler JL (2016a) Secondary invasion: The bane of weed management. Biological Conservation 197: 8-17. https://doi.org/10.1016/j.biocon.2016.02.029

Pearson DE, Ortega YK, Eren Ö, Hierro J (2016b) Quantifying “apparent” impact and distinguishing impact from invasiveness in multispecies plant invasions. Ecological Applications 26: 162-173. https://doi.org/10.1890/14-2345

Peters MA, Hamilton D, Eames C (2015) Action on the ground: a review of community environmental groups' restoration objectives, activities and partnerships in New Zealand. New Zealand Journal of Ecology 39(2): 179-189.

Prior KM, Adams DC, Klepzig KD, Hulcr J (2018) When does invasive species removal lead to ecological recovery? Implications for management success. Biological Invasions 20: 267283. https://doi.org/10.1007/s10530-017-1542-x

Reid AM, Morin L, Downey PO, French K, Virtue JG (2009) Does invasive plant management aid the restoration of natural ecosystems? Biological Conservation 142: 2342-2349. https://doi.org/10.1016/j.biocon.2009.05.011 
Rinella MJ, Maxwell BD, Fay PK, Weaver T, Sheley RL (2009) Control effort exacerbates invasive-species problem. Ecological Applications 19: 155-162. https://doi.org/10.1890/071482.1

Ruwanza S, Gaertner M, Esler KJ, Richardson DM (2018) Medium-term vegetation recovery after removal of invasive Eucalyptus camaldulensis stands along a South African river. South African Journal of Botany 119: 63-68. https://doi.org/10.1016/j.sajb.2018.08.002

Schuster MJ, Wragg PD, Reich PB (2018) Using revegetation to suppress invasive plants in grasslands and forests. Journal of Applied Ecology 55(5): 2362-2373. https://doi. org/10.1111/1365-2664.13195

Shackleton RT, Le Maitre DC, van Wilgen BW, Richardson DM (2017) Towards a national strategy to optimise the management of a widespread invasive tree (Prosopis species; mesquite) in South Africa. Ecosystem Services 27: 242-252. https://doi.org/10.1016/j. ecoser.2016.11.022

Sher AA, Gieck S, Brown CS, Nissen SJ (2008) First-year responses of cheatgrass following Tamarix spp. control and restoration-related disturbances. Restoration Ecology 16: 121135. https://doi.org/10.1111/j.1526-100X.2008.00355.x

Skurski TC, Maxwell BD, Rew LJ (2013) Ecological tradeoffs in non-native plant management. Biological Conservation 159: 292-302. https://doi.org/10.1016/j.biocon.2012.10.017

Vosse S, Esler KJ, Richardson DM, Holmes PM (2008) Can riparian seed banks initiate restoration after alien plant invasion? Evidence from the Western Cape, South Africa. South African Journal of Botany 74: 432-444. https://doi.org/10.1016/j.sajb.2008.01.170

Wilson JR, Panetta FD, Lindgren CJ (2017) Detecting and Responding to Alien Plant Incursions. Cambridge University Press, Cambridge, 265 pp. https://doi.org/10.1017/ CBO9781316155318

Yelenik SG, Stock WD, Richardson DM (2004) Ecosystem level impacts of invasive Acacia saligna in the South African fynbos. Restoration Ecology 12: 44-51. https://doi. org/10.1111/j.1061-2971.2004.00289.x 